\title{
Intra-articular injection in the hind limb joints of dromedary camels (Camelus dromedarius) using anatomical and arthrographic-guided landmarks
}

\author{
Fahd Al-Sobayil ${ }^{(D)}$, Madeh A. Sadan ${ }^{1,2}$ (D) Elsayed A. El-Shafaey ${ }^{1,3}$ (iD) and Jamal Allouch $1,4(\mathbb{D}$
}

1. Department of Veterinary Medicine, College of Agriculture and Veterinary Medicine, Qassim University, Qassim, Saudi Arabia; 2. Department of Surgery, Anesthesiology and Radiology, Faculty of Veterinary Medicine, South Valley University, Qena 83523, Egypt; 3. Department of Surgery, Anesthesiology and Radiology, Faculty of Veterinary Medicine, Mansoura University, Mansoura 35516, Egypt; 4. Department of Anatomy, AL-Baath University, Syria.

Corresponding author: Madeh A. Sadan, e-mail: madehsadan@vet.svu.edu.eg

Co-authors: FA: fsobayil@hotmail.com, EAE: sayedelshafaey@yahoo.com, JA: gentle187@hotmail.com Received: 23-01-2021, Accepted: 11-06-2021, Published online: 10-08-2021

doi: www.doi.org/10.14202/vetworld.2021.2055-2063 How to cite this article: Al-Sobayil F, Sadan MA, El-Shafaey EA, Allouch J (2021) Intra-articular injection in the hind limb joints of dromedary camels (Camelus dromedarius) using anatomical and arthrographic-guided landmarks symptoms, Veterinary World, 14(8): 2055-2063.

\begin{abstract}
Background and Aim: A healthy joint is an important structure for the proper movement of the camel limb. Intra-articular (IA) injection is frequently used in veterinary practice for diagnostic and therapeutic purposes of joint injuries. Thus, the current study aimed to describe the injection of the hindlimb joints in dromedary camels based on the anatomical and arthrographic-guided landmarks.

Materials and Methods: Eighteen orthopedically sound adult camels (mean \pm standard deviation age: $78 \pm 12$ months) of both sexes were included in this study. Three camels were euthanized to identify anatomical features in the hindlimb joints and related structures. IA injections were performed in the hindlimbs of 5 camel cadavers to evaluate the optimal IA injection site, which was confirmed by arthrography. The optimized IA injection technique was applied in 10 live camels and confirmed by arthrocentesis and arthrography. For each joint, injection criteria (number of attempts, difficulty of injection, and successful injection) were assessed, scored, and statistically compared to the other joints.
\end{abstract}

Results: The summation of IA injection criteria scores was significantly higher $(\mathrm{p}<0.05)$ in the femorotibial, femoropatellar, tibiotarsal, fetlock, pastern, and coffin joints in comparison to the hip joint.

Conclusion: Anatomical and arthrographic-guided techniques offer considerable advantages for the characterization of anatomical landmarks and selection of the appropriate IA injection site in the hindlimb in dromedary camels. Furthermore, a reference approach for camels was established that is different from the approach for cattle and horses.

Keywords: anatomical, arthrographic, camels, hindlimb, intra-articular injection.

\section{Introduction}

The worldwide population of dromedary camel (Camelus dromedarius) is approximately 14 million, distributed mainly in the Horn of Africa, the Middle East, and South Asia [1]. Dromedary camels are an important source of milk, meat, wool, and leather production and are also used for draught and riding purposes. Camel races are a popular sport in many countries and represent an important economic sector for income and tourism in these countries [2].

A healthy joint is an important structure for the proper movement of the camel limb. Intra-articular (IA) injection is frequently used in veterinary practice for diagnostic and therapeutic purposes and is increasingly used for the early diagnosis of joint injury [3-8]. This technique is easy to perform, cost-effective, and

Copyright: Al-Sobayil, et al. Open Access. This article is distributed under the terms of the Creative Commons Attribution 4.0 International License (http://creativecommons.org/licenses/ by/4.0/), which permits unrestricted use, distribution, and reproduction in any medium, provided you give appropriate credit to the original author(s) and the source, provide a link to the Creative Commons license, and indicate if changes were made. The Creative Commons Public Domain Dedication waiver (http:// creativecommons.org/publicdomain/zero/1.0/) applies to the data made available in this article, unless otherwise stated. requires no special equipment [9]. Many reports have described hindlimb IA injection in horses [10-12], cattle [13], and small animals [14]. However, to the best of our knowledge, no comprehensive articles describe IA injection of the hindlimb in camels; hence, approaches described for horses or cattle have been widely applied to camels without verifiable data.

In the present study, we described the injection of the hindlimb joints in dromedary camels based on the anatomical and arthrographic-guided landmarks. A reference approach for the camel was established that is different from the approaches taken in cattle and horses.

\section{Materials and Methods}

\section{Ethical approval}

The study protocol was approved by the Committee of Animal Welfare and Ethics, Faculty of Agriculture and Veterinary Medicine, Qassim University, Saudi Arabia.

\section{Study period and location}

The study was carried out from October 2019 to October 2020 in the Veterinary Teaching Hospital at the Qassim University Faculty of Veterinary Medicine, Saudi Arabia. 


\section{Animals}

Eighteen adult camels (Mean \pm standard deviation age: $78 \pm 12$ months) of both sexes were included in this study. Camels were purchased from different localities of the Qassim Governorate, Saudi Arabia. All camels were clinically sound without a previous history of lameness or joint affection.

\section{Study design}

The study was carried out in three parts, including anatomical, cadaveric, and in vivo studies. In the anatomical study, three freshly euthanized camels were used for the anatomical division of the hind limb joints. In the cadaveric study, five camel cadaver hindlimbs were used to evaluate the optimal site for IA injection and the injection site was confirmed by arthrography. In the in vivo study, ten live healthy adult camels were used to evaluate the in vivo accuracy of blind IA injections of the hindlimbs based on the cadaveric IA trials.

\section{Anatomical study}

Three camels were randomly selected and euthanized using a high dose of rapid intravenous $30 \mathrm{mg} / \mathrm{kg}$ thiopental sodium (Thiowell 1\%, Wellona Pharma 243, Surat, Gujarat, India). The anatomical landmarks of the hind limb joints and related structures for the correct IA injection were determined. The hindlimb cadavers were collected within $12 \mathrm{~h}$ of euthanasia. The specimens were moistened, wrapped in gauze, sealed in plastic bags, and stored at $-20^{\circ} \mathrm{C}$. For all investigations, limbs were thawed to room temperature, clipped, and cleaned. Anatomical landmarks of the hindlimb joints were evaluated and photographed by an expert anatomist (GA) with the aid of correlated anatomical references, for comparison to the corresponding arthrographic images. The hindlimb anatomical landmarks for the appropriate IA injection site were identified based on the anatomical features of each joint (articular surfaces, ligaments, synovial cavities, and the distance from the skin surface to the target joint).

\section{Cadaveric study}

In the cadaveric study, IA injection sites for each hindlimb joint were shaved and thoroughly cleaned with warm water and soap. The limb was positioned in a suitable attitude for injection of each joint of the hindlimb. For all specimens $(n=5)$, the injection of the hindlimb joint was performed by an experienced veterinary surgeon (EE). An adequate volume (10-50 mL, depending on the joint) of radiopaque iopamidol contrast agent (Scanlux $® 300$, Sanochemia Pharmazeutika AG-Germania) was injected with minimal pressure into each joint, according to Alsobayil et al. [15]. Immediately after injection, the injected joint was fully flexed and extended 3 times. Subsequently, lateromedial (LM) and dorsoplantar (DP) radiographic projections of each joint were obtained using a Min X-ray HF 100/30 generator (Toshiba, Tokyo, Japan) with $70 \mathrm{kVp}, 2.0 \mathrm{mAs}$, and $70 \mathrm{~cm}$ focal film distance. The operator considered the needle to be inserted into the joint space if the contrast agent injection met with little resistance, there was visible distension of the joint pouch, or the fluid could be retrieved following injection. The success of the injection was confirmed by the presence of contrast agent in the joint. The approach and landmarks for IA injection of each hindlimb joint were based on the following procedures:

\section{Coffin joint}

IA injection of the coffin joint was performed approximately $5 \mathrm{~cm}$ medial or lateral to the vertical midline of the digit. The needle was inserted distally in the ventrolateral or ventromedial direction perpendicular to the bearing surface of the foot (Figure-1).

\section{Pastern joint}

Injection of the pastern joint required continuous flexion and extension of the joint. The joint space was easily palpated with firm finger pressure just below the distal condyle of the first phalanx. The needle was inserted on the dorsal midline between the medial and lateral eminences on the distal end of the proximal phalanx and distally directed slightly medially or laterally (Figure-1).

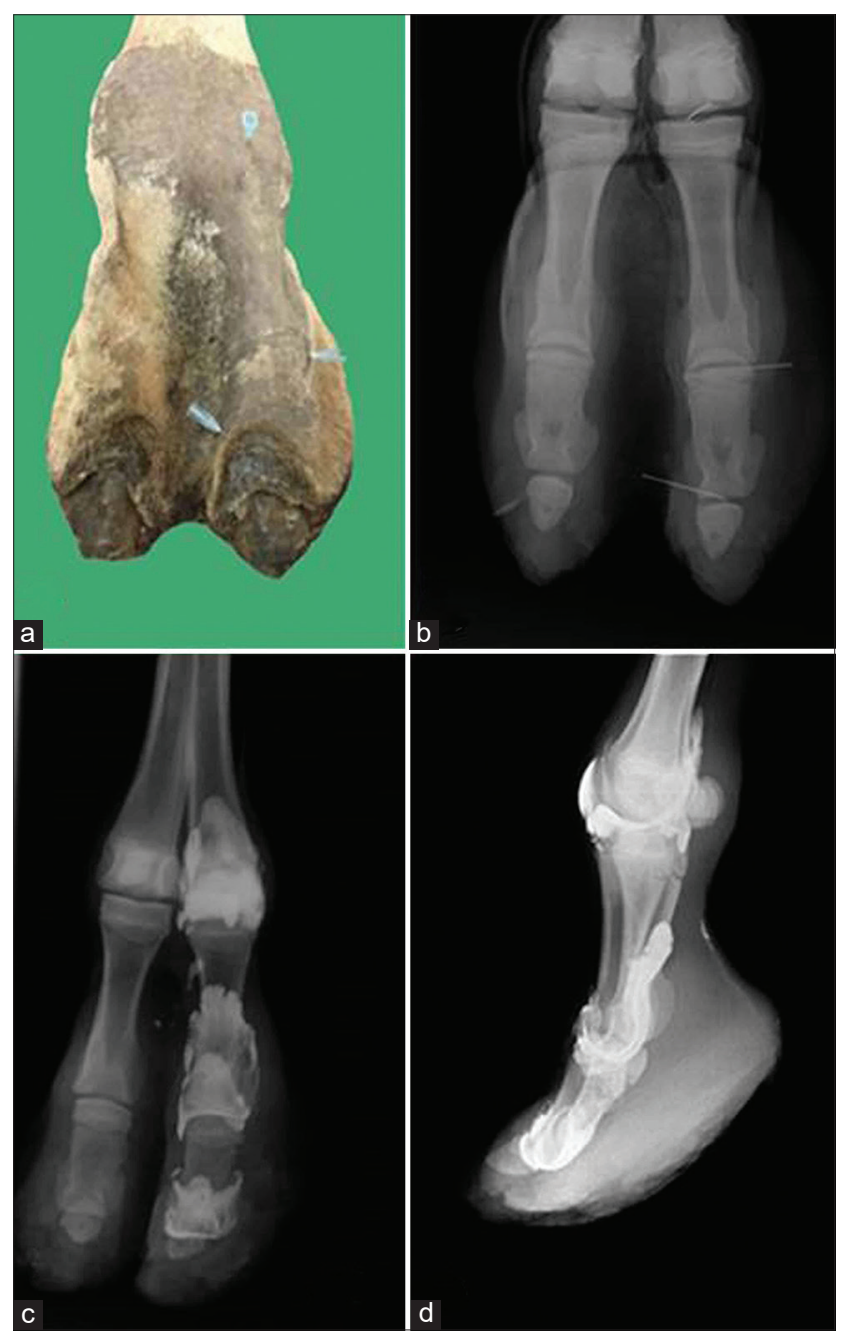

Figure-1: Sites for injection of the fetlock, pastern and coffin joints in a dromedary camel hind limb (a), dorsoplantar radiograph showing needle placement in the fore mentioned joints (b), dorsoplantar (c), and lateromedial (d) arthrograms of the fetlock, pastern, and coffin joints in the same camel. 


\section{Fetlock joint}

The needle was inserted at the midline through the dorsal aspect of the fetlock joint capsule at or slightly above the palpable joint space and perpendicular to the skin surface immediately proximal to the head of the $1^{\text {st }}$ phalanx. The needle went through the digital extensor tendon and was directed medially and parallel to the frontal plane of the joint to enter the dorsal pouch of the fetlock joint (Figure-1).

\section{Tarsal joint}

The tarsal joint is composed of four joints: The tibiotarsal, proximal intertarsal, distal intertarsal, and tarsometatarsal joints (Figure-2a-d). Various approaches were tried for IA injection of the tarsal joint; the dorsal approach was the most feasible, especially with the tarsus extended (Figure-2). The tarsometatarsal joint was injected through dorsal, caudolateral, or caudomedial approaches. For the dorsal approach, the needle was inserted at the depression between the fused $2^{\text {nd }}$ and $3^{\text {rd }}$ tarsal bone and the $4^{\text {th }}$ tarsal bone. For the caudolateral or caudomedial approaches, the needle was inserted downward just proximal to the $4^{\text {th }}$ or the $2^{\text {nd }}$ metatarsal bone, respectively (Figure- $2 \mathrm{a}$ and $\mathrm{b}$ ). The dorsomedial approach was used for IA injection of the distal intertarsal joint. The needle was directed dorsally in a depression formed between the central and the $4^{\text {th }}$ tarsal bones or just distal to the central tarsal bone (Figures-2a and b). An alternative approach for the distal intertarsal joint involved an indirect injection through the connection with the tarsometatarsal joint. The proximal intertarsal joint was injected dorsolaterally (just below the distal end of the calcaneus) or dorsomedially (proximal to the central tarsal bone) (Figures-2a and $\mathrm{b}$ ). In addition, dorsal injection of the tibiotarsal joint was achieved by inserting the needle ventrolateral to the tibial cochlea in a caudal and slightly proximal direction (Figures-2e and f).

\section{Stifle joint}

The stifle joint consists of two joints, the femoropatellar joint and the femorotibial joint. For IA injection of the femoropatellar joint, the stifle joint was flexed and the dorsoproximal and distal ends of the patella and femur, respectively, were palpated. The needle was inserted distally between the patella and the femur in a slightly dorsal direction (Figures-3a-c). The femorotibial joint was injected dorsally from the lateral or medial sides (Figures-3d-f). For both sides, the patellar ligaments and the lateral or medial patellar retinaculum were palpated. In the dorsolateral approach, the needle was inserted between the palpable lateral patellar ligament and the lateral patellar retinaculum or just lateral to the lateral patellar retinaculum, directly above the palpable proximomedial edge of the tibia. In the dorsomedial approach, the needle was inserted between the medial patellar ligament and the medial patellar retinaculum or just medial to the medial patellar retinaculum above the palpable proximomedial edge of the tibia (Figures-3g and $h$ ).
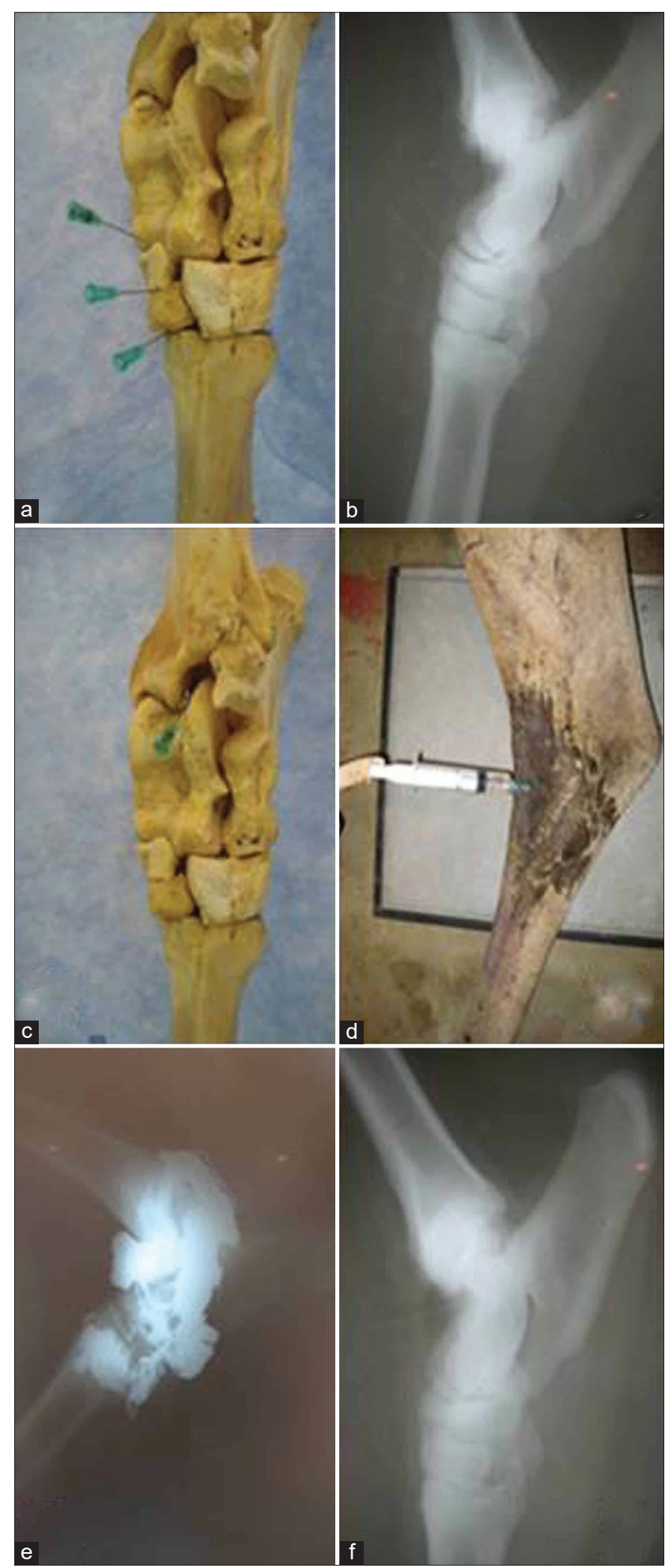

Figure-2: Sites for injection of the tarsometatarsal, distal intertarsal and proximal intertarsal joints in camel (a), Lateromedial (LM) radiograph showing needle placement in the fore mentioned joint (b), Site for injection of the tibiotarsal joint (c), Injection technique of the tibiotarsal joint in camel (d), LM arthrograms showing intra-articular presence of the contrast agent and needle after successful injection of the tarsal joint in camel (e and $f$ ).

\section{Hip joint}

The hip joint was blindly injected by inserting the needle at the intersection point above the palpable edge of the greater trochanter and directing the needle perpendicular to the vertebral column in the distomedial 


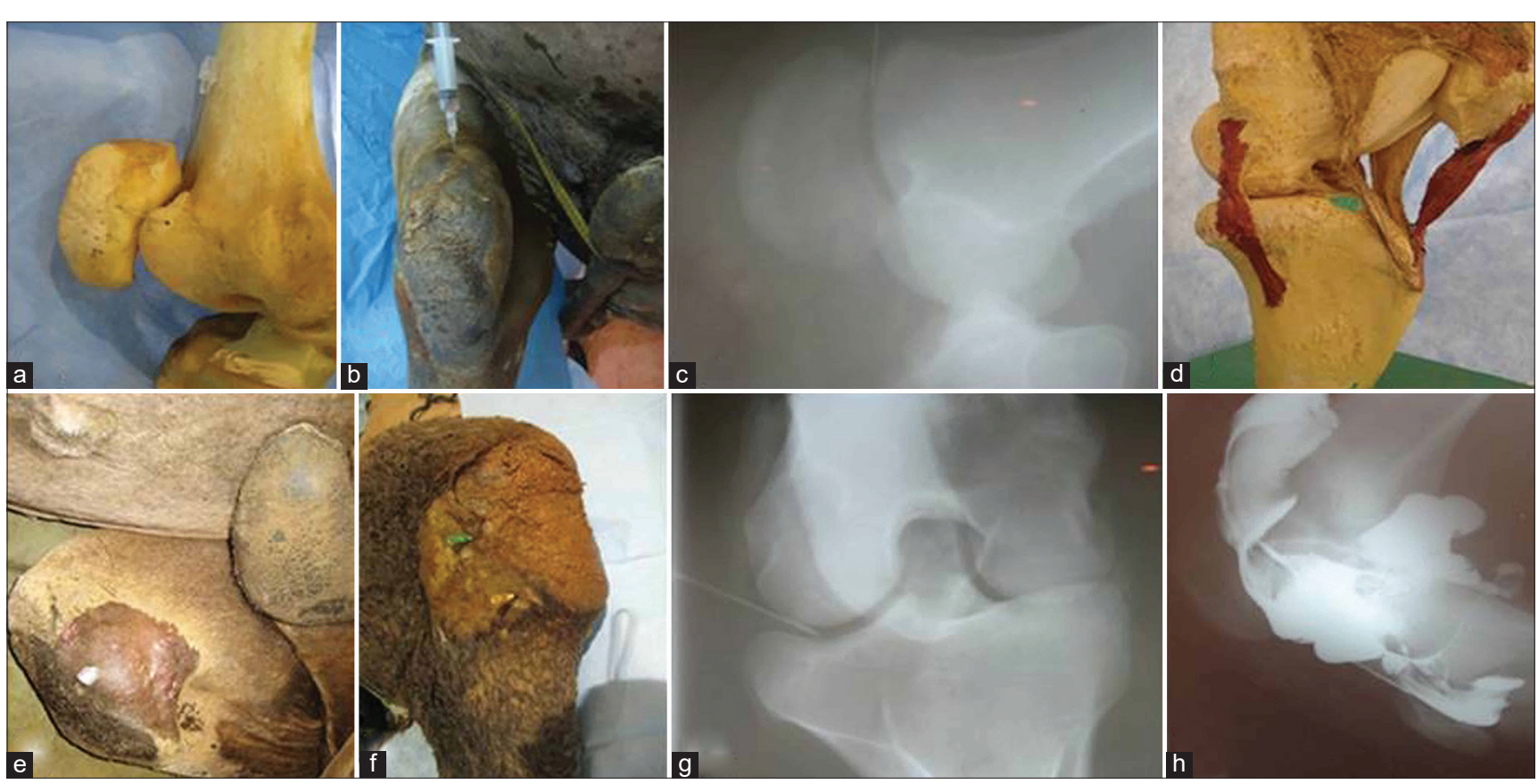

Figure-3: Site for injection of the femoro-patellar joint in camel (a), Injection technique of the forementiond joint in a live dromedary camel (b), Lateromedial (LM) radiograph showing correct needle placement for injection of the femoropatellar joint (c), Site for injection of the femerotibial joint in camel (d), Injection technique of the forementiond joint in live dromedary camels (e and f), LM arthrograms showing intra-articular presence of the contrast agent and needle after successful injection of the stifle joint in camel ( $g$ and $h)$.

direction (Figures-4a and b). Positioning the camel in a lateral recumbent position and flexing the stifle joint was optimal for injection of the hip joint. This position facilitated the palpation of the greater trochanter, especially in thin camels (Figures-4c and d).

\section{In vivo study}

To assess the reliability and accuracy of blind IA injections of the camel hindlimb, ten live healthy adult camels were used. The procedure was performed while the camels were sitting and sedated with xylazine hydrochloride (Seton 2\%, Laboratorios Calier, S.A., Barcelona, Spain) at a dose of $0.2 \mathrm{mg} / \mathrm{kg}$, IV. Each joint was aseptically prepared and injected blindly with needles of appropriate gauge and length.

\section{Evaluation parameters}

Data for each IA injection were collected, including the number of attempts, difficulty of injection, and successful injection of each joint. Descriptive details of the scores and definitions of the hindlimb IA injection criteria are described in Table-1.

\section{Statistical analysis}

Statistical analysis was performed using the GraphPad Prism statistical software program (GraphPad Prism for Windows version 5.0, GraphPad Software Inc., USA). The IA injection criteria scores were compared among the hindlimb joints by the Kruskal-Wallis nonparametric ANOVA test. Differences were considered significant when $p<0.05$.

\section{Results}

\section{Anatomical findings}

Gross dissection was performed for each joint as part of the anatomical study. The skin and muscles

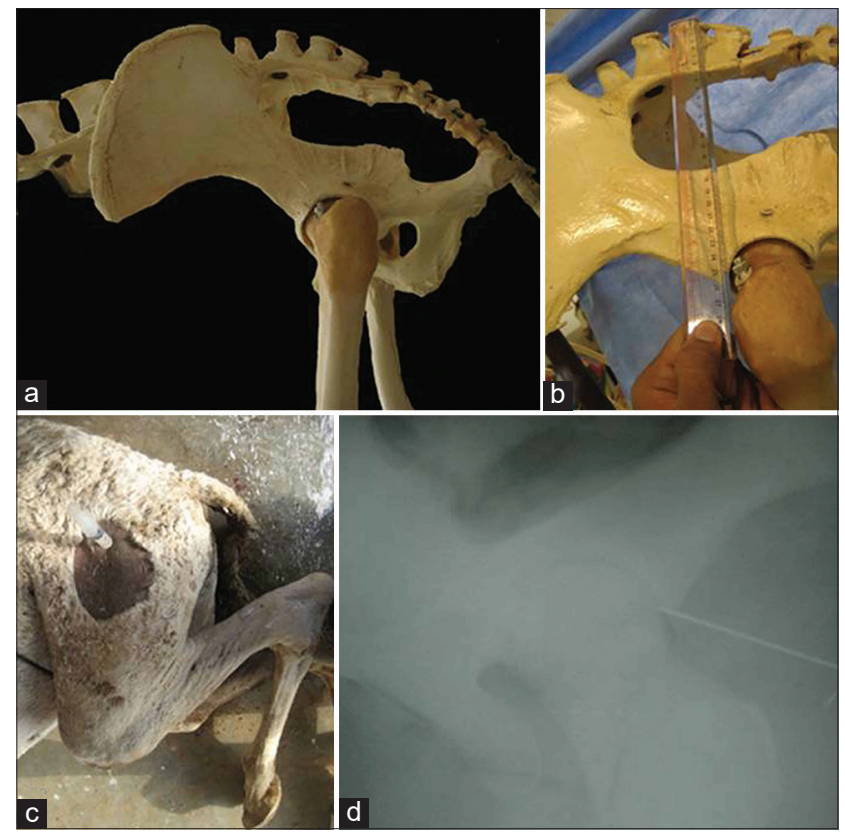

Figure-4: The anatomical intersection point for hip injection in camel ( $a$ and $b)$, Injection technique of the hip joint in a dromedary camel (c), Lateromedial radiograph showing correct intr-articular placement of the needle for injection of the hip joint in camel (d).

related to each joint were carefully removed exposing the joint capsule. Gross anatomical dissection showed the numerous structures (articular structures, ligaments, blood vessels, and nerves) that were vulnerable to injury during needle insertion. Articular surfaces, ligaments, and synovial cavities were differentiated well (Figures-1-4). The mean distance from the skin surface to the target joint was about $3.0 \pm 0.25 \mathrm{~cm}$ and 
differed according to the site of the joint and its surrounding structures.

\section{Cadaveric findings}

IA injection of the camel's hindlimb was practical, reliable, and accurate. The anatomical landmarks determining the point of needle insertion for each joint were successfully identified in all cadavers and the joints were properly injected in all instances, as confirmed by arthrography (Figures-1-4). On plain and contrast arthrography, the anatomical features of each joint were readily distinguished. Each joint in the hindlimb of the dromedary camel could be precisely discriminated using anatomical and arthrographic-guided techniques.

The IA injection criteria scores were significantly higher $(\mathrm{p}<0.05)$ in the femorotibial, femoropatellar, tibiotarsal, fetlock, pastern, and coffin joints compared with the hip joint. The number of attempts and the difficulty of injection were significantly lower in the femorotibial, femoropatellar, tibiotarsal, fetlock, pastern, and coffin joints than in the other joints. The lowest successful injections were recorded for the hip joint compared with the other joints. The median and range of the criteria for IA injection of all camel hindlimbs are presented in Table-2.

\section{Arthrographic findings}

Arthrography of camel hindlimbs provided images with well-differentiated radiographic features of the synovial cavities for the evaluated joints (Figures-1-4). In addition, IA needle placement in the target joint and filling of the articular compartment with the contrast media was confirmed. For most of the hindlimb joints, a 20-22-gauge, 1-inch needle was optimal for IA injection. For the tibiotarsal, stifle, and hip joints, an 18 -gauge, 1.5 -inch needle was best. Descriptive details of the IA injection approaches and arthrographic features of the hindlimb joints on the DP and LM radiographs in dromedary camels are presented in Table-3.

\section{In vivo findings}

The IA injection technique for the hindlimb was well tolerated in live camels. No differences in the injection technique between in vivo and cadaveric studies were observed. Identification of the bony landmarks for IA injection of the hindlimbs was possible in all cases. Arthrocentesis was attempted before each injection. Then, the needle was advanced about $3-5 \mathrm{~cm}$ deep and limb retraction with resistance to injection was observed in two camels for the hip joint. In those animals, the needle was withdrawn and reinserted until positive arthrocentesis. Successful IA injection was achieved in all cases without any gross orthopedic abnormalities during or following the procedures. The average number of attempts required to inject the joint successfully was 1-3 and was higher in the hip joint.

\section{Discussion}

A sound IA injection technique with a high success rate is essential for proper joint manipulation
Table-1: Injection criteria scores for subjective assessment of the intraarticular injection of the hindlimb in dromedary camels.

\begin{tabular}{ll}
\hline Criteria & Score and description \\
\hline Number of & $0=$ Success with $\geq 3^{\text {rd }}$ attempt \\
attempts & $1=$ Success with $2^{\text {nd }}$ attempt \\
& $2=$ Success with $1^{\text {st }}$ attempt \\
Difficulty & $0=$ Difficult, several attempts with low \\
of injection & confidence \\
& $1=$ Moderate, several attempts until \\
& successful injection \\
& $2=$ Easy, immediate and confident injection \\
Successful & $0=$ Poor, periarticular $>5 \mathrm{~mm}$ from the \\
injection & target joint \\
& $1=$ Good, periarticular $<5 \mathrm{~mm}$ from the \\
& target joint \\
& $2=$ Excellent, intraarticular of the target \\
& joint
\end{tabular}

Table-2: Median and range for subjective evaluation of injection criteria scores for intraarticular injection of the hindlimb in all investigated Dromedary camels.

\begin{tabular}{|c|c|c|c|}
\hline \multirow[t]{2}{*}{ Joint } & \multicolumn{3}{|c|}{$\begin{array}{c}\text { Injection criteria (Median and } \\
\text { range) }\end{array}$} \\
\hline & $\begin{array}{c}\text { Number of } \\
\text { attempts }\end{array}$ & $\begin{array}{c}\text { Difficulty } \\
\text { of injection }\end{array}$ & $\begin{array}{c}\text { Successful } \\
\text { injection }\end{array}$ \\
\hline Coffin joint & $0(0-0)^{a}$ & $0(0-0)^{\mathrm{b}}$ & $0(0-0)^{c}$ \\
\hline Pastern joint & $0(0-0)^{a}$ & $0(0-0)^{b}$ & $0(0-0)^{c}$ \\
\hline Fetlock joint & $0(0-0)^{a}$ & $0(0-0)^{b}$ & $0(0-0)^{c}$ \\
\hline \multicolumn{4}{|l|}{ Tarsal joint } \\
\hline $\begin{array}{l}\text { Tarsometatarsal } \\
\text { joint }\end{array}$ & $1(1-2)^{b}$ & $1(1-2)^{b}$ & $2(1-2)^{a}$ \\
\hline $\begin{array}{l}\text { Distal intertarsal } \\
\text { joint }\end{array}$ & $1(1-2)^{b}$ & $1(1-2)^{b}$ & $2(1-2)^{a}$ \\
\hline $\begin{array}{l}\text { Proximal } \\
\text { intertarsal joint }\end{array}$ & $1(1-2)^{b}$ & $1(1-2)^{b}$ & $2(1-2)^{a}$ \\
\hline Tibiotarsal joint & $2(1-2)^{a}$ & $2(2-2)^{a}$ & $2(1-2)^{a}$ \\
\hline \multicolumn{4}{|l|}{ Stifle joint } \\
\hline $\begin{array}{l}\text { Femuropatellar } \\
\text { joint }\end{array}$ & $2(1-2)^{a}$ & $2(2-2)^{a}$ & $2(1-2)^{a}$ \\
\hline Femurotibial joint & $2(1-2)^{a}$ & $2(2-2)^{a}$ & $2(1-2)^{a}$ \\
\hline Hip joint & $0(0-0)^{a}$ & $0(0-0)^{\mathrm{b}}$ & $1(0-1)^{a}$ \\
\hline
\end{tabular}

$a, b, c$ : Medians and ranges with different superscript letters at the same column are significantly different at $p<0.05$

in farm animals $[13,16]$. Horse and cattle are often used as models for IA injection of large animal limbs. However, IA injection cannot be based on standard data from these animals and should be evaluated separately for the camel; there are methodological aspects of the camel that warrant further characterization. In addition, the occupation, anatomical variations in body size, height, and weight, and genetics of horses and cattle are different from camels and these differences can influence the correct limb injection $[15,17]$. Thus, the aim of this study was to investigate the efficacy of IA injection of the hindlimb joint using anatomical and arthrographic-guided landmarks, as an aid to clinicians performing arthrocentesis or injection.

To the best of our knowledge, this is the first study describing IA injection of the camel hindlimb. In the present study, no signs of articular injury were observed during injection of the hindlimb joints in live 
Table-3: Intraarticular approaches and arthrographic features of the hindlimb joints on the dorsoplantar (DP) and lateromedial (LM) arthrograms in camels.

\begin{tabular}{|c|c|c|c|c|c|c|}
\hline \multirow[t]{2}{*}{ Joint } & \multirow{2}{*}{$\begin{array}{l}\text { Intraarticular } \\
\text { approach }\end{array}$} & \multirow{2}{*}{$\begin{array}{l}\text { Contrast } \\
\text { volume } \\
(\mathrm{mL})\end{array}$} & \multicolumn{2}{|c|}{ Needle } & \multirow[t]{2}{*}{ DP radiograph } & \multirow[t]{2}{*}{ LM radiograph } \\
\hline & & & $\begin{array}{l}\text { Diameter } \\
\text { (gauge) }\end{array}$ & $\begin{array}{l}\text { Length } \\
\text { (inch) }\end{array}$ & & \\
\hline Coffin joint & $\begin{array}{l}\text { Dorsomedial/ } \\
\text { dorsolateral }\end{array}$ & $10-15$ & $20-22$ & 1 & $\begin{array}{l}\text { Large square joint with } 2 \\
\text { short proximally oriented } \\
\text { recesses. }\end{array}$ & $\begin{array}{l}\text { It forms a large plantar } \\
\text { sinus that extends to the } \\
\text { middle of the } 2^{\text {nd }} \text { phalanx. } \\
\text { The entire of coffin joint had } \\
\text { small dorsal sinus. }\end{array}$ \\
\hline Pastern joint & $\begin{array}{l}\text { Dorsomedial/ } \\
\text { dorsolateral }\end{array}$ & $15-20$ & $20-22$ & 1 & $\begin{array}{l}\text { Large rectangular } \\
\text { joint with } 2 \text { short axial } \\
\text { and abaxial recesses } \\
\text { extended distally. }\end{array}$ & $\begin{array}{l}\text { It has a dorsal pouch and } \\
\text { a long plantar pouch, } \\
\text { extended to the middle of } \\
\text { the } 1^{\text {st }} \text { phalanx. The dorsal } \\
\text { pouch was narrower than } \\
\text { the plantar one }\end{array}$ \\
\hline Fetlock joint & Dorsal & $20-25$ & $20-22$ & 1 & $\begin{array}{l}\text { It has } 2 \text { separate medial } \\
\text { and lateral joint cavities. } \\
\text { It appeared triangle } \\
\text { in shape with its base } \\
\text { directed distally and an } \\
\text { apex directed proximally. }\end{array}$ & $\begin{array}{l}\text { Appeared as a crescent with } \\
\text { a relatively long plantar } \\
\text { recess and short dorsal one. }\end{array}$ \\
\hline Tarsal joint & & & & & The joint spaces & Appeared large and irregular \\
\hline $\begin{array}{l}\text { Tarsometatarsal } \\
\text { joint }\end{array}$ & $\begin{array}{l}\text { Dorsal/ } \\
\text { Caudomedial/ } \\
\text { caudolateral }\end{array}$ & $10-15$ & $20-22$ & 1 & $\begin{array}{l}\text { between the various } \\
\text { articulations of the } \\
\text { tarsal joint (tarsocrural, }\end{array}$ & $\begin{array}{l}\text { in shape with } 2 \text { cranial and } \\
\text { caudal pouches. The caudal } \\
\text { pouch is larger and longer }\end{array}$ \\
\hline $\begin{array}{l}\text { Distal } \\
\text { intertarsal joint }\end{array}$ & Dorsomedial & $10-15$ & $20-22$ & 1 & $\begin{array}{l}\text { talocalcaneal, intratarsal } \\
\text { and tarsometatarsal }\end{array}$ & $\begin{array}{l}\text { than the cranial one. It } \\
\text { extends proximally from the }\end{array}$ \\
\hline $\begin{array}{l}\text { Proximal } \\
\text { intertarsal joint }\end{array}$ & $\begin{array}{l}\text { Dorsomedial/ } \\
\text { dorsolateral }\end{array}$ & $10-15$ & $20-22$ & 1 & joints) could be assessed. & $\begin{array}{l}\text { tibiotarsal joint and distally } \\
\text { up to the tarsometatarsal }\end{array}$ \\
\hline Tibiotarsal joint & Dorsal & $25-35$ & 18 & 1.5 & & $\begin{array}{l}\text { joint. While, the cranial } \\
\text { pouch extends only up to the } \\
\text { proximal intertarsal joint. }\end{array}$ \\
\hline Stifle joint & & & & & A small dorsal recess was & It has a large and small \\
\hline $\begin{array}{l}\text { Femuropatellar } \\
\text { joint }\end{array}$ & Dorsal & $30-40$ & 18 & 1.5 & $\begin{array}{l}\text { detected and extended } \\
\text { up to the proximal dorsal }\end{array}$ & $\begin{array}{l}\text { cranial and caudal pouch, } \\
\text { respectively; both of them }\end{array}$ \\
\hline $\begin{array}{l}\text { Femurotibial } \\
\text { joint }\end{array}$ & $\begin{array}{l}\text { Dorsomedial/ } \\
\text { dorsolateral }\end{array}$ & $35-50$ & 18 & 1.5 & end of the tibia. & $\begin{array}{l}\text { were extended along the } \\
\text { whole length of the joint. }\end{array}$ \\
\hline Hip joint & Lateral & $25-30$ & 18 & 1.5 & $\begin{array}{l}\text { The pelvis symphysis } \\
\text { and coccygeal vertebrae } \\
\text { are positioned in a } \\
\text { straight line parallel to } \\
\text { the midline. Both sides } \\
\text { of the pelvic bones are } \\
\text { symmetric. }\end{array}$ & $\begin{array}{l}\text { Identified as the intersection } \\
\text { point between } 2 \text { imaginary } \\
\text { lines: a straight horizontal } \\
\text { line starting from the } \\
\text { ischium tuberosity and a } \\
\text { vertical straight line starting } \\
\text { from the root of the tail. }\end{array}$ \\
\hline
\end{tabular}

camels. Anatomical and arthrographic guidance facilitated the identification of anatomical landmarks, needle placement, and selectivity of the IA approach in camel hindlimbs. Similar findings were in agreement with previously published $[9,18,19]$.

In the present study, a cadaveric model was employed to investigate IA injection techniques in the camel hindlimb. The accuracy rates for injection of the hindlimb joints in camel cadavers were as high as desired and were in agreement with previously published reports $[15,20]$. Moreover, there were no significant differences in IA injection success and techniques between fresh cadavers and live camels. The in vivo study was performed to exclude the possibility that the temperament, pain, and movement of the live camel during injection could change the results.

Contrast injection followed by radiography is a superior method for detecting extra-articular injection. Dissection depends on every plane of tissue being exactly exposed, whereas radiographic contrast is easily detected in a single radiograph [19]. In this study, arthrography of the hindlimb joints provided high-quality images in which well-differentiated features of the synovial cavities could be observed. In addition, arthrography was used to confirm successful injection through IA localization of the needle or contrast agent.

Several full flexions or extensions were essential for increasing the joint space to facilitate IA injection of the limb. Injections of hind limb joints in camels were easily performed after flexion, except for the tarsal joint. In the tarsal joint, extension facilitated injection and these findings were in accordance with the previous publications [12,21].

In this study, all IA injection approaches were successful and easy to perform with a low risk of articular cartilage damage. Scores for all injection criteria in the femorotibial, femoropatellar, tibiotarsal, fetlock, pastern, and coffin joints were higher compared with the injection criteria scores for the hip joint. The 
lower injection criteria score for the hip was due to the deep location of the joint beneath heavy muscle and well away from the lateral aspect of the proximal end of the femur. This location made the identification of landmarks difficult. These findings were in agreement with previously published studies [22,23].

In camels, IA injection of the coffin joint was performed with the needle inserted distally in the ventrolateral or ventromedial direction and perpendicular to the bearing surface of the foot. The optimal landmarks established in this study are similar to those previously established in the camel forelimb coffin joint $[15,24,25]$. However, in horses and cattle, the proper site for puncturing the coffin joint is proximal to the coronary band with the needle directed toward the extensor process of the $3^{\text {rd }}$ phalanx $[22,26]$.

In horses, injection of the pastern joint can be performed by inserting the needle on the vertical midline above the proximal epicondyle of the second phalanx $[7,10,21]$. However, in camels, the joint space was easily palpated just below the distal condyle of the first phalanx. Thus, in camels, the optimal site for insertion of the needle was on the dorsal midline between the medial and lateral eminences on the distal end of the proximal phalanx.

Puncturing of the fetlock joint, in this study, was easily performed by the dorsal approach, especially with digit flexion. This was in agreement with a previous report [18]. However, the fetlock joint of horses can be entered using palmar/plantar and dorsal approaches [13,27].

In this study, the tarsal joint could be successfully injected utilizing several approaches. For selecting the proper clinical approach, reducing the time required and the necessity for potentially painful needle repositioning are important safety considerations for both the clinician and the camel. Injection of the distal intertarsal joint is technically more difficult than the tarsometatarsal joint because of its medial approach. Thus, this approach presents more danger to the clinician. The distal intertarsal joint can be simultaneously injected with the proximal joint through the tarsometatarsal joint because of the direct communication between the two joints. Moreover, the tibiotarsal joint is the easiest of all joints to inject because of its thin capsule and the obvious landmarks. The anatomical landmarks for a dorsal approach to joint injection are more distinct for the tibiotarsal joint, which may account for the reduced number of needle manipulations required for this approach. These observations were in agreement with previously published reports [28-32]. In horses, similar approaches were used for injection of the tarsal joint except for the distal intertarsal joint, which was injected laterally [33-35].

In horses, cranial and lateral approaches have been described for injection of the femoropatellar joint and the medial and lateral approaches have been described for injecting the femorotibial joint. However, in camels, we found that the optimal approach for the femoropatellar joint injection was dorsal to the stifle joint and the optimal approach for the femorotibial joint was dorsomedial or dorsolateral to the stifle joint $[7,19]$.

In our study, the hip joint was blindly injected through a lateral approach by inserting the needle in the intersection point above the palpable edge of the greater trochanter and directing it perpendicular to the vertebral column in a distomedial direction. However, in horses, the dorsal approach is better for injection of the hip joint using blind or ultrasound-guided techniques $[7,23,36]$.

Needle placement is a challenge for safe and effective IA injection techniques $[9,12]$. Needle placement is affected by several factors, including needle diameter and length and anatomical and radiographic features of the target joint. In camels, data to support a standard technique are lacking $[15,18]$. In this study, we found that a needle diameter and length of 20-22 gauges and 1 inch were appropriate for IA injection of most hindlimb joints. To ensure adequate needle localization, anatomical and arthrographic-guided landmarks were used. Similar recommendations were advised in the previous studies [20,37].

One challenging limitation in the IA injection of the camel limb is the evaluation of proper needle placement in relation to the target joint without complications. The criteria score system for evaluating injection techniques provided a simple tool for subjective assessment of the efficacy and success rates of IA injection techniques. These findings were in agreement with the previous studies $[15,16]$.

IA injection of the camel limb is a relatively feasible and affordable radiation-free imaging tool that is easy to perform in skilled hands with minimal risks. IA injection is also cost-effective and requires no special equipment under field conditions. Moreover, IA injection can easily be incorporated into a diagnostic or therapeutic procedure of the joints. These findings are in agreement with previously published reports [19]. On the contrary, the use of blind IA injection has several limitations, including a needle insertion based on palpation of surface anatomic landmarks without visual control. This may result in incorrect needle placement and inadequate injection [23,36,37]. Therefore, further studies are necessary to evaluate other imaging-guided techniques versus blind ones to validate the effectiveness in clinical situations.

\section{Conclusion}

Anatomical and arthrographic-guided techniques offer considerable advantages for the characterization of anatomical landmarks, needle placement, and selection of the appropriate site for IA injection of the hindlimb in dromedary camels. This study establishes a reference approach based on camel arthrography, which is different from cattle and horses. To the best of the authors' knowledge, this is the first study of IA injection of the hindlimb in dromedary camels. 


\section{Authors' Contributions}

FA, MAS, and EAE: Concept and designed the study. FA, MAS, EAE, and JA: Performed the experimental section. EAE and MAS: Analyzed and interpreted the data. All authors revised and approved the final manuscript.

\section{Acknowledgments}

The authors are thankful to the staff of the Department of Veterinary Medicine, College of Agriculture and Veterinary Medicine, Qassim University, Saudi Arabia, for cooperation in the study. The authors did not receive any funds for this study.

\section{Competing Interests} interests.

The authors declare that they have no competing

\section{Publisher's Note}

Veterinary World remains neutral with regard to jurisdictional claims in published institutional affiliation.

\section{References}

1. Al Haj, O.A. and Al Kanhal, H.A. (2010) Compositional, technological and nutritional aspects of dromedary camel milk. Int. Dairy. J., 20(12): 811-821.

2. Abdul Rahim, S.A., Abdul Rahman, K. and El-Nazier, A.E. (1994) Camel production and reproduction in Qassim, Saudi Arabia. J. Arid Environ., 26(1): 53-59.

3. Abdel Maksoud, M.K.M. (2020) Normal anatomic reference of pastern and coffin joints in Egyptian buffalo (Bubalus bubalis): A compared atlas of cross-sectional anatomy, magnetic resonance imaging and computed tomography. Anat. Histol. Embryol., 49(2): 290-298.

4. Abdel Maksoud, M.K.M. (2021) Gross anatomical, computed tomographic and magnetic resonance imaging study of the metacarpo/metatarsophalangeal joint in Egyptian buffalo (Bubalus bubalis). Anat. Histol. Embryol., 50(2): 360-372.

5. Abdellatif, A.M., Hamed, M.A., El-Shafaey, E.S. and Eldoumani, H. (2018) Normal magnetic resonance anatomy of the hind foot of Egyptian buffalo (Bubalus bubalis): A correlative low-field T1- and T2-weighted MRI and sectional anatomy atlas. Anat. Histol. Embryol., 47(6): 599-608.

6. Ayman, E., Usama, H., Walter, B., Ramadan, O.R., Adel, A. and Kerstin, G. (2015) Computed tomography of the hind limbs in healthy dromedary camel foot. J. Vet. Med. Anim. Prod., 6(2): 98-102.

7. Baxter, G.M. and Stashak, T.S. (2011) Peri-neural and intra-synovial Anaesthesia. In: Adams, S. and Baxter, G.M., editors. Lameness in Horses. $6^{\text {th }}$ ed. John Wiley \& Sons, United States. p173-202.

8. Leighton, R., Akermark, C., Therrien, R., Richardson, J.B., Andersson, M., Todman, M.G. and Arden, N.K. (2014) NASHA hyaluronic acid vs. methylprednisolone for knee osteoarthritis: A prospective, multicentre, randomized, non-inferiority trial. Osteoarthritis Cartilage, 22(1): 17-25.

9. Courtney, P. and Doherty, M. (2009) Joint aspiration and injection and synovial fluid analysis. Best. Pract. Res. Clin. Rheumatol., 23(2): 161-192.

10. Just, E.M., Patan, B. and Licka, T.F. (2007) Dorsolateral approach for arthrocentesis of the centrodistal joint in horses. Am. J. Vet. Res., 68(9): 946-952.

11. Ross, T.N., Kisiday, J.D., Hess, T. and McIlwraith, C.W. (2012) Evaluation of the inflammatory response in experimentally induced synovitis in the horse: A comparison of recombinant equine interleukin 1 beta and lipopolysaccharide. Osteoarthritis Cartilage, 20(12): 1583-1590.

12. Waxman, S.J., Adams, S.B. and Moore, G.E. (2015) Effect of needle brand, needle bevel grind, and silicone lubrication on contamination of joints with tissue and hair debris after arthrocentesis. Vet. Surg., 44(3): 373-378.

13. Blaser, M., Bertagnoli, A., Räber, M., Nuss, K., Rasekh, M. and Steiner, A. (2012) Arthroscopic approaches to the fetlock joint of adult cattle: A cadaver study. Vet. J., 193(3): 701-706.

14. Smith, G.N., Myers, S.L., Brandt, K.D. and Mickler, E.A. (1998) Effect of intra-articular hyaluronan injection in experimental canine osteoarthritis. Arthritis Rheum., 41(6): 976-985.

15. Alsobayil, F.A., Allouch, J.A. and Ahmed, F.A. (2015) Articular puncture techniques and contrast arthrography of the forelimb in dromedary camels (Camelus dromedarius). Pak. Vet. J., 35(1): 28-32.

16. Moyer, W. and Schumacher, J. (2011) Equine Joint Injection and Regional Anesthesia. $5^{\text {th }}$ ed. Academic Veterinary Solutions, Chadds Ford, USA. p70-73.

17. Badawy, A.M. (2011) Computed tomographic anatomy of the fore foot in one-humped camel (Camelus dromedarius). Glob. Vet., 6(4): 417-423.

18. Bani Ismail, Z., Al-Rukibat, R., Al-Tarazi. Y. and Al-Zghoul, M.B. (2007) Synovial fluid analysis and bacterial findings in arthritic joints of juvenile male camel (Camelus dromedarius) Calves. J. Vet. Med. A Physiol. Pathol. Clin. Med., 54(2): 66-69.

19. Fahmy, L.S., Mostafa, M.B., Farag, K.A. and Hegazy, A.A. (1996) Arthrography of the elbow and carpal joints in the camel (Camelus dromedarius). J. Camel. Pract. Res., 3(2): 119-124.

20. Francoz, D., Desrochers, A. and Latouch, J. (2007) Effect of repeated arthrocentesis and single joint lavage on cytologic evaluation of synovial fluid in 5 young calves. Can. J. Vet. Res., 71(2): 129-134.

21. Poore, L.A., Lambert, K.L., Shaw, D.J. and Weaver, M.P. (2011) Comparison of three methods of injecting the proximal inter-phalangeal joint in horses. Vet. Rec., 168(11): 302-305.

22. Harper, J., Schumacher, J., Degraves, F., Schramme, M. and Schumacher, J. (2007) Effects of analgesia of the digital flexor tendon sheath on pain originating in the sole, distal interphalangeal joint or navicular bursa of horses. Equine Vet. J., 39(6): 535-539.

23. Mary, B.W., Betsy, V., Scott, K. and Jake, H. (2016) Ultrasound-guided injections in horses with cranioventral distension of the coxofemoral joint capsule: Feasibility for cranioventral approach. Vet. Radiol. Ultrasound, 57(2): 199-206.

24. Hamed, M., El-Shafaey, E.S., Abo Elfadl, E. and Abdellatif A. (2020) Intra-articular injection techniques of the buffalo (Bubalus bubalis) hindlimb digit using anatomical and contrast arthrography-guided landmarks. Acta Vet. Hung., 68(3): 310-317.

25. Nourinezhad, J., Mazaheri, Y. and Ahi, M.R. (2015) Metrical analysis of dromedary digital bones. Anat. Sci. Int., 90(2): 113-122.

26. van Amstel, S. and Shearer, J. (2006) Manual for Treatment and Control of Lameness in Cattle. Blackwell Publishing Co., Iowa, USA. p24.

27. Alrtib, A.M., Philip, C.J., Abdunnabi, A.H. and Davies, H.M.S. (2013) Morphometrical study of bony elements of the forelimb fetlock joints in horses. Anat. Histol. Embryol., 42(1): 9-20.

28. Ehlert, A., Ferguson, J. and Gerlach K. (2011) Magnetic resonance imaging and cross sectional anatomy of the normal bovine tarsus. Anat. Histol. Embryol., 40(3): 234-240.

29. Hagag, U., Brehm, W., Ramadan, R.O., Al Mubarak, A., El Nahas, A. and Gerlachm, K. (2013) Computed tomography and cross-sectional anatomy of the normal dromedary 
camel tarsus (one humped camel). Anat. Histol. Embryol., 42(4): 266-274.

30. Hagag, U., Tawfiek, M., Brehm, W. and Gerlach K. (2016) Computed tomography of the normal bovine tarsus. Anat. Histol. Embryol., 45(6): 469-478.

31. Hoaglund, E.L., Seabaugh, K.A., Selberg, K.T., Hess, A. and Bass, L. (2019) Comparing the clinical success rate of the dorsolateral approach to the medial approach for injection of the centrodistal joint in the horse. Equine Vet. J., 51(6): 795-801.

32. Jones, M.L., Washburn, K.E., Fajt, V.R., Rice, S. and Coetzee, J.F. (2015) Synovial fluid pharmacokinetics of tulathromycin, gamithromycin and florfenicol after a single subcutaneous dose in cattle. BMC. Vet. Res., 7(11): 26-33.

33. Raes, E.V., Bergman, E.H., van der Veen, H., Vanderperren, K., van der Vekens, E. and Saunders, J.H. (2011) Comparison of cross-sectional anatomy and computed tomography of the tarsus in horses. Am. J. Vet. Res.,
72(9): 1209-1221.

34. Serena, A., Schumacher, J. and Schramme, M.C. (2005) Concentration of methylprednisolone in the centrodistal joint after administration of methylprednisolone acetate in the tarsometatarsal joint. Equine Vet. J., 37(2): 172-174.

35. Vanderperren, K., Martens, A., Haers, H., Duchateau, L. and Saunders, J.H. (2009) Arthroscopic visualization of the third metacarpal and metatarsal condyles in the horse. Equine Vet. J., 41(6): 526-533.

36. David, F., Rougier, M., Alexander, K. and Morisset, S. (2007) Ultrasound-guided coxofemoral arthrocentesis in horses. Equine Vet. J., 39(1): 79-83.

37. El-Shafaey, E., Hamed, M., Abdellatif, A. and Abo Elfadl, E. (2017) Comparison of blind, ultrasound and computed tomographic-guided injection techniques for nerve block of the head in one-humped camel (Camelus dromedaries) cadavers. Pak. Vet. J., 37(2): 180-184.

$* * * * * * * *$ 